\title{
Engaging Patients with Eating Disorder to Treatment via Collaborative Understanding of their Emotional Issues Across Lifespan
}

\section{Moria Golan*}

Tel Hai Academic College and the Hebrew University of Jerusalem, Israel

\begin{abstract}
Most patients with eating disorder (ED) are ambivalent regarding change. The more severe the eating disorder, symptoms are perceived as being preferable to the alternative distresses and patients present negative coping mechanisms such as denial and/or opposition to treatment.

This report describes clinically driven strategy for engaging patients with eating disorders to therapeutic process. It describes a structured procedure for the preliminary meeting with the patient focusing on developmental tasks, difficulties and coping mechanisms.

There is an emphasis on the process of achieving collaboratively narration of the context in which the eating disorder invaded and how it relates to the patients' emotional issues across the life span, as well as the etiological theories in which it is rooted. We review the patients' history from childhood through adolescence or adulthood, exploring the nature of emotional and developmental difficulties in the different ages. We track how they impacted the person's behaviors, personality and coping mechanisms, as well as the reasons he/she was tempted to the eating disorders' 'shelter'. A dynamic understanding, motivational interviewing, and engagement in externalizing conversation are the means used to reveal the prices and motivate the patient to take control of his/her life and choose to be treated.
\end{abstract}

Keywords: Eating disorders; Motivational interviewing intake; Developmental narration

\section{Introduction}

Patients with eating disorders (ED) often resist treatment. Denial and resistance to change are prominent features in most patients with ED [1]. The ego syntonic quality of symptoms can contribute to ambivalence and avoidance of treatment, difficulties in establishing a therapeutic relationship and high rates of attrition and relapse $[2,3]$.

Ambivalence regarding recovery has been understood as expression of selfless souls with difficulties in achieving self-regulation, calming, soothing, and vitalizing [4,5]. Symptoms are perceived as being preferable to the alternative distresses since they present a coping mechanism against ego weakness, anxiety, and interpersonal factors $[6,7]$ as well as high-reward dependence, arrested self-development [810]. Awareness of ambivalence seemed to encompass two aspects: inner struggle and fear of recovery. On one hand, the desire for recovery and on the other hand, the desire to restrict themselves and struggle for thinness. Inner struggle may reinforce the fear of recovery and vice versa [11].

This manuscript describes clinically driven developmental narration in the first session, aimed to engage patients in the therapeutic proces. This session has been named as the 'preliminary phase' in our model published recently and as "intake" by others [12].

The life story can serve to unify contextual and diachronic elements of the self, while also distinguishing this self from others. Due to the conceptual overlap between self-continuity and identity it is perhaps unsurprising that the life story and identity have often been equated [13]. The purpose of developmental narration is to deconstruct 'problem saturated identity conclusions' and understand them in the context of the biological and psychological characteristics in the person's life [13].

\section{First steps towards patients engagement}

The evaluation and engagement session aims at getting to know the client, his/her problem, achieving mutual understanding of the context in which the ED invades his life and how it relates to the patients' emotional issues along lifespan. Revealing the prices of having $\mathrm{ED}$, frequently motivates the patient to take control of his/her life and choose to be treated. Such understanding often assists patients to retain the sense of control on their lives, which echoes the need for control that characterizes individuals with ED [14].

Part of the "therapeutic partnership" is achieved via collaborative review of the patients' developmental narrative in respect to affect, fears and impulsivity features. It is done using a dynamic understanding, motivational interviewing [15] and engaging in an externalizing conversation (position the illness external to the patient) [16] contradicting most patients' perceptions that they themselves are the essence of the problem. The patients are reassured that the vital, compensatory aspects of the psychopathology are deeply understood and that their apprehensions will be carefully appraised in shaping the interventions undertaken. Furthermore, changes sought will be measured against their tolerance to the anxieties that may be triggered $[17,18]$.

\section{Case illustration}

Noaa, a 20 years old female who had struggled with bulimia nervosa for the past three years. She had been referred to us by the eating disorders department where she was hospitalized for the last 3 months and had been discharge due to lack of collaboration. Noa came into the room with the filled demographic and personal details questionnaire. After a brief glance, I reflected that she had been through many interventions and I wondered what will be a success treatment for

*Corresponding author: Prof. Golan Moria, Tel Hai Academic College and the Hebrew University of Jerusalem, Israel, Tel: 972-547240330; Fax: 97289348798; E-mail: moria.golan@mail.huji.ac.il

Received May 31, 2014; Accepted July 02, 2014; Published July 15, 2014

Citation: Golan M (2014) Engaging Patients with Eating Disorder to Treatment via Collaborative Understanding of their Emotional Issues Across Lifespan. J Psychol Abnorm Child 3: 123. doi:10.4172/2329-9525.1000123

Copyright: (C) 2014 Golan M. This is an open-access article distributed under the terms of the Creative Commons Attribution License, which permits unrestricted use, distribution, and reproduction in any medium, provided the original author and source are credited. 
her? Noaa reported on having an all-or-nothing pattern of eating. Her BMI was 22 and she was constantly preoccupied with feeling fat and wanting to lose weight. She expressed her wishes to be able to return to work, study and have an independent life but she will collaborate only if she is promised to lose weight. I reflected that her ED subjects terms to normal occupation. I reframed the temptation to comply with ED messages, as a mean to minimize danger and maximize reward which is a basic process in human being survival [14]. This opening usually results in a sense of relief among patients. They start to fill being understood.

Then, we gently unfold the regulatory issues, fears, desires, selfcontrol issues, social difficulties, personality traits, family conflicts, and the coping strategies endorsed (tendency to deny or avoid conflicts) from infancy to present, as was suggested by Vanderlinden [19].

Noa described her early fears from strangers, avoiding sleeping out of home. I reflected on biological origins of anxiety axis and further explored its nature in the different ages.

Table 1 presents the anamnesis features explored in each life period, the personal perceptions derived and the theoretical orientation explaining its relation to the eating disorder.

Each stage of life is approached with the question: what kind of a person were you then? Which characteristics and behaviors will be best describing you by your friends/family members?

Each answer is reflected to induce a sense of understanding and sometimes a suggestion is offered as to how it is related to the eating disorder.

During early adolescence, Noaa described frequent outburst and tyranny behaviors towards friends and family members. I had suggested presence of features from the impulse/drives axis as well, and we further explored the expression of these features later in life.

I frequently ask for permission to convey complex reflections or interpretation about its relation to the evolution of ED. If the patient disagrees with my interpretation I acknowledge his view and empower his sincere dialogue and guidance. During this conversation, Noa started to understand how the eating disorder and her emotional issues are related. She could see the association between her regulatory issues during infancy and childhood, its formation changes during adolescents and how her sense of "being not good enough" has been developed. The idea of 'fixing' herself by achieving thinness has been widely discussed.

This conversation was finalized with a few directive questions about obsessive-compulsive symptoms, sexual injury and presence of ED in other family members.

\section{Narrating the foundation of ED via review of developmental stages}

We than shortly explore the impact of ED on patients life covering many aspects (physically, cognitively, emotionally, socially, self and body image, status in the family). We shortly discuss the patients' coping mechanisms that were exploited by ED as well as explore the sense of control, safety, uniqueness, maturity arrest suggested by ED and at the same time the prices (physically, cognitively, emotionally, socially, self and body image, status in the family).

I ask for permission to narrate the whole conversation, making it easier to understand the life-span germination, and the 'doors' through which ED invaded as well the defense mechanisms that nurtured its maintenance. For the narration, I use Figure 1.

Figure 2 illustrates the narration of the case example.

I conclude with asking the patient if this narration fits his/her view and invite him/her to alter or reflect on it.

After getting permission from the patient, I invite his/her parents into the room and share with them the story of how we (s/he and I) understood the problem roots. I re-tell the story of the problem's evolution, how it invaded the family life, and which conflicts through the life span it took advantage of. When the story is told again (with the parents) and parents' recognition of the problem origin, is achieved, patient often feels understood, trusts the treatment provider and is more ready to enter a meaningful bond and consider treatment as an option.

This developmental narration, respecting the patient's ability to gain from such developmental understanding, relates to patients as an agent, despite their condition. It provides them a sense of agency and even choice and control at least to a degree, reducing their tendency to take a passive or a resistant role.

\section{Session structure}

- Each patient arrives to the intake session with the following documents: forms filled with personal details, ED assessment

Questionnaires, history of previous treatments and parental view of the problem and of patient's symptoms.

- In the following 60-90 minutes, I converse with the patient, collaboratively understanding the factors in his life, which brought up the process of being tempted to get a shelter under the eating disorder's umbrella.

- Parents are invited to join us to the last 30 minutes. I portray the problem narration, unfolding its early seeds, while asking the parents to fill possible gaps.

- Finally, I summarize the "solutions/illusions" provided by ED, summarize the qualities and advantages that were taken from the patient by ED and challenge the patient position towards it.

Overall such a session lasts 90-120 minutes.

\begin{tabular}{|l|l|l|l|}
\hline Periods in Life & Features explored & Derived needs/perception & Theoretical orientation \\
\hline Infancy & Temper, Sensitivity & Needs maternal preoccupation, Vulnerable & Regulation theories \\
\hline Childhood & $\begin{array}{l}\text { Tantrum, Outburst, Maladaptive behaviors, Anxiety } \\
\text { features Diseases/Traumas }\end{array}$ & Destructive, Powerless, Vulnerable & Regulation theories, Ego theories \\
\hline Primary school & $\begin{array}{l}\text { ADHD, Crippleness, Social difficulties, Familial } \\
\text { difficulties }\end{array}$ & $\begin{array}{l}\text { Lack of Self-Control Impotent, Defective, } \\
\text { Worthless, Low self-Confidence, }\end{array}$ & $\begin{array}{l}\text { Self-theories, Regulation theories } \\
\text { Developmental theories family theories }\end{array}$ \\
\hline Adolescents & $\begin{array}{l}\text { Identity formation issues, Sexual and religious } \\
\text { identity issues, Social difficulties, Familial difficulties }\end{array}$ & $\begin{array}{l}\text { Lack of uniqueness, "too much", "not enough", } \\
\text { life "too large on me", not understood, isolated }\end{array}$ & $\begin{array}{l}\text { Self-theories, Developmental theories, } \\
\text { Social theories, Family theories }\end{array}$ \\
\hline
\end{tabular}

Table 1: The anamnesis features explored in each life period, the personal perceptions derived and the theoretical orientation explaining its relation to the eating disorder 
Citation: Golan M (2014) Engaging Patients with Eating Disorder to Treatment via Collaborative Understanding of their Emotional Issues Across Lifespan. J Psychol Abnorm Child 3: 123. doi:10.4172/2329-9525.1000123

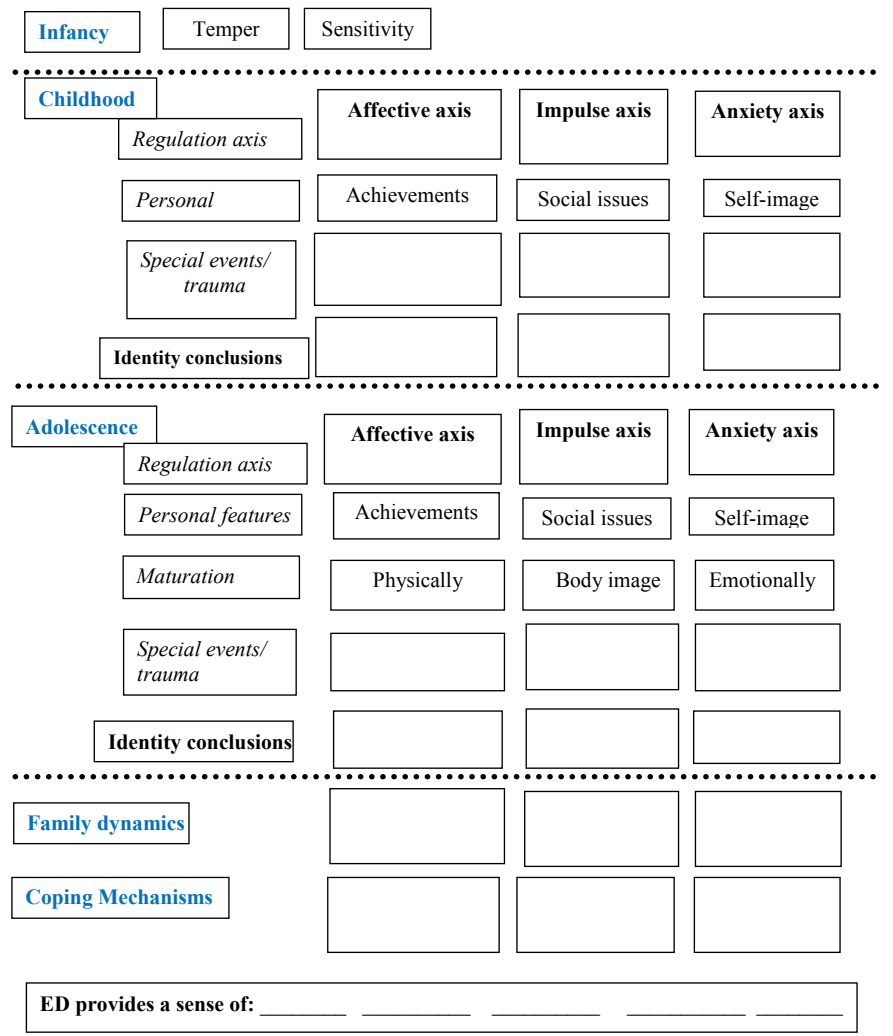

Figure 1: The Problem Narration.

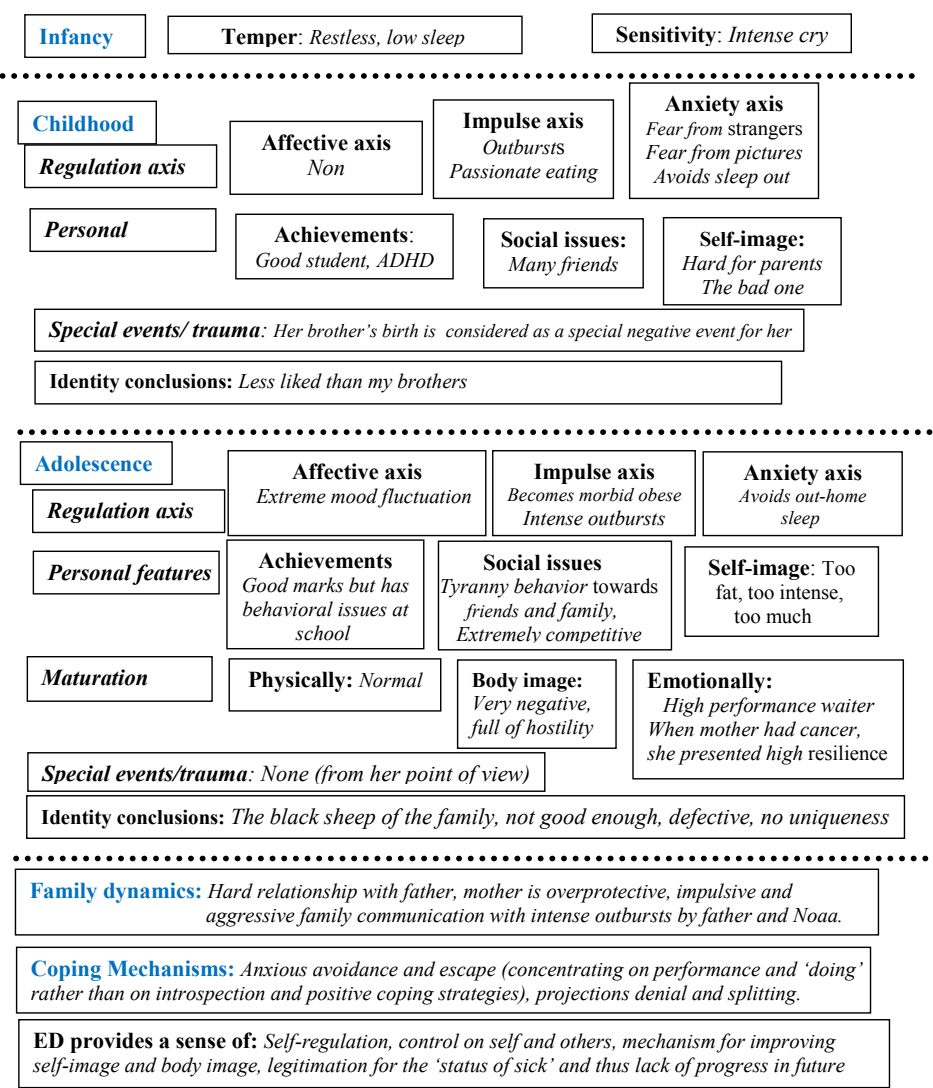

Figure 2: Noa's Problem Narration. 


\section{Discussion}

Engaging ED patients in treatment is a challenging task. The described process of engaging patients and parents to the developmental context in which the eating disorder invaded, has been developed in the context of working with people with eating disorders and their families.

Asking for permissions as well as sharing reflections with the patients and get their approval for the therapists understanding, provide them with a sense of control and self-agency on the narrative created, sense of being understood and not isolated as well as becoming less defensive because their ambivalence is explored.

The combination of developmental, narrative and motivational approach has formed the basis for many therapeutic models over the years $[18,20,21]$. Each of these models approach the patients with different strategies but with similar spirit: emphasizing partnership, honoring patient's expertise and perspectives, affirming of patient's right and capacity for understanding the context of the illness development as well as ways to cope with it.

Although such an intake is time consuming, it is theory based, can be delivered by therapists from different professional backgrounds and the potential for change is enhanced through a sense of collaborative understanding and empowerment of the patients who frequently present a sense of inferiority [22].

\section{Conclusions}

The described tool is a useful heuristic to help patients and their families understand the many factors that contribute to the illness and what plays a role in its persistence, as well as suggest how treatment can challenge them.

\section{Acknowledgment}

The author thanks the Israeli Shahaf's team and patients for being part of this enthusiastic journey.

\section{References}

1. Hart LM, Granillo MT, Jorm AF, Paxton SJ (2011) Unmet need for treatment in the eating disorders: A systematic review of eating disorder specific treatment seeking among community cases. Clin Psychol Rev 31: 727-735.

2. Vitousek K, Watson S, Wilson GT (1998) Enhancing motivation for change in treatment-resistant eating disorders. Clin Psychol Rev 18: 391-420.

3. Mander J, Teufel M, Keifenheim K, Zipfel S, Giel KE (2013) Stages of change treatment outcome and therapeutic alliance in adult inpatients with chronic anorexia nervosa. BMC Psychiatry 13: 111.

4. Goodsit A (1977) Eating disorders: A self-psychological perspective. In: D. Garner, and P. E. Garfinkel (Eds.) Handbook of psychotherapy for eating disorders, The Guilford Press. New York.

5. Kohut $H$ (1977) Preface to psychodynamics of drug dependence. In: J. D. Blaine and D. A. Julius (Eds.), Psychodynamics of drug dependence, Washington, DC: GPO.

6. Bion W (1959) Attacks on linking. In: E. Spillius, (Ed) Melaine Klein today: developments in theory and practice, Routledge, London
7. Bruch H (1982) Anorexia Nervosa: therapy and theory. Am J Psychiatry 139 : 1531-1538.

8. Crisp A H (1980) Anorexia nervosa: Let Me Be, Academic press, London.

9. Strober M (1991) Disorders of the self in anorexia nervosa: an organismicdevelopmental paradigm. In: C. Johnson, (Ed), Psychodynamic treatment of anorexia nervosa and bulimia, Guilford Press, New York.

10. Vitousek KB, Ewald LS, (1993) Self-representation in eating disorders: a cognitive perspective. In: Z. V. Segal and S. J. Blatt (Eds.) The self in emotional disorders: cognitive and psychodynamic perspectives, The Guilford Press, New York.

11. Gorse P, Nordon C, Rouillon F, Pham-Scottez A, Revah-Levy A (2013) Subjective motives for requesting in-patient treatment in female with anorexia nervosa: a qualitative study. PLoS One 8: e77757.

12. Golan M (2013) The journey from opposition to recovery from eating disorders: multidisciplinary model integrating narrative counseling and motivational interviewing in traditional approaches. Journal of Eating Disorders 1: 19-27.

13. Dunlop WL, Walker LJ (2013) The life story: Its development and relation to narration and personal identity. International Journal of Behavior and Development 5: 1-13.

14. Reid M, Burr J, Williams S, Hammersley R (2008) Eating disorders patients' views on their disorders and on an outpatient service: a qualitative study. Health Psychol 13: 956-960.

15. Rollnick S, Miller, WR, Butler C (2008) Motivational interviewing in health care: helping patients change behavior. The Guildford Press, New York.

16. White M, Epston D (1989) Literate means to therapeutic ends. Adelaide: Dulwich Centre Publications.

17. Leichner $P$ (2005) A new treatment approach to treating eating disorders in youth. BC Medical Journal 47: 23-27.

18. Bryant-Waugh $R$ (2006) Pathways to recovery: promoting change within a developmental-systemic framework. Clin Child Psychol Psychiatry 11: 213-224.

19. Vanderlinden $\mathrm{J}(2010)$ Do different psychopathological pathways into eating disorder necessitates different therapeutic goals and/or approaches? Eur Eat Disord Rev Reviews 18: 161-164.

20. Fallon P, Wisniewski L (2013) A system of evidenced-based techniques and collaborative clinical interventions with a chronically ill patient. Int J Eat Disord 46: 501-506.

21. Werner-Wilson RJ (2001) Developmental-systemic family therapy with adolescents. Haworth Press, New York.

22. Williams LM, Gatt JM, Hatch A, Palmer DM, Nagy M, et al. (2008) The integrate model of emotion, thinking and self regulation: an application to the "paradox of aging". J Integr Neurosci 7: 367-404. 